of diet should be adopted which experience has proved best adapted to keep the system in full health and strength without overloading it with useless material. No tendency to congestion or plethora should be encouraged. An occasional purgative, active exercise in the open air, a moderate share of rest, due use of bathing, and, above all, a cheerful, active, and well-poised mind-these are the conditions most likely to resist the attacks of any epidemic, particularly the one in question. In addition to this, everything which may happen to be wrong about the health should be rectified as soin as possible. Costiveness should be prevented, headaches should be cured, hamorrhages should be stanched, any irregularities of the female system should be corrected, and protracted lactation should at once come to an end. In addition to this, those persons who live in constant dread of epidemics should be admonished to take measures to get their apprehensions dissipated; to consult their medical adviser, who, if they require it, may possibly suggest something which may tend to prepare the system for the attack if it should really seize them; but, abore all, to make use of the suggestions of common sense, which, whether guided by the dictates of religion or of philosophy, teaches that the dread of coming ills is, of all ills, the most afflictive, and that, when every reasonable precaution has heen adopted, a trustful, quiet mind is the best protection for the body, just as it is the safest condition for the soul.

Alfred-place, Bedford-square, Oct. 1852.

\section{ON STRICTURE OF THE URETHRA, WITH A NEW METHOD OF TREATING THE DISEASE.} BY W. J. MLORE, EsQ.

LATE RESIDENT SURGEON AT THE QUEEX'S HOSPITAL, BIRMINGHAM.

Having, during the last three years, paid considerab'e attentiun to diseases of the genito-urinary organs, particularly stricture of the urethra, I am induced to lay before the profession a means of treatment by dilutation, which, so far as 1 am aware, has never before been practised or proposed. Althourh so much has of late been said on the subject, it is generally admitted that all the raried plans now advocated are open to serions objections. The treatment by dilatation as ordinarily practised often fails; frequently a catheter of even moderate size may be passed one day, and on the next, owing to spasm, congestion, or subacute inflammatory action, no instrument can be used. Retaining the catheter in the passage is also unsafe; inflammation of the bladder, peritonitis, abscess, \&c., not nnfrequently arising. The caustic treatment is now almost universally deprecated. Professor Syme's plan is only applicable to certain obstinate cases, where the passage of instruments cannot be borne, or when such treatment has failed. The metallic stricture dilator, lately brought forward, is open to the objection of expanding more in the anterior part of the urethra than the posterior, in which latter portion of the passage it is evident the expansive force is mostly required. Mr. Wakley's instruments are certainly the best yet in general use, and have proved, in my hands, productive of much good but the interior of the urethra is liable to suffer by the passage of the hollow tubes over the straight staff.

From a consideration of these and other circumstances, I came to the conclusion, that could a thin, expansible substance be introduced into the urethra, to serve as a sort of false lining membrane, dilatation might be practised to any extent by expanding, with a larger instrument, sound, or catheter, the expansible material already introduced. Under this impression, I applied to several manufacturers of gutta percha and India-rubber articles, and finally obtained some tubes from Messrs. Mackintosh, of Liverpool, which partly answered the purposes required. They were, however, too thick and clumsy in every way, so that it was necessary to have a new set prepared on a smaller scale. The material used in their manufacture is, I believe, a mixture of gutta percha and caoutchouc, with here and there a thread introduced for security and strength. The tubes themselves are rather longer that an ordinary catheter, and the smallest very thin, and of sufficient calibre inside to receive a small wire stilet. The stilet, thus enclused in the expansible case, is carried through the stricture into the bladder; the wire is then withdrawn, and a larger wire, catheter, or sound, well oiled, passed in its stead within the expansible case already present for its reception. Thus dilatation may be carried to any extent without risk of producing laceration of the urethra, false passage, hæmorrhage, or other accident. A command of the passage may also be retained by allowing the flexible tube to remain, which may be done without risk of suppuration or irritation, for days together ; the urine being drawn off once or twice daily by means of a catheter, the boles at the end of the instrument of course corresponding with other apertures at the extremity of the dilatable tube.
I feel assured of the efficacy of this mode of treatment, and of the value of the flexible tubes, from the results of several cases where I have used them, but think that the tubes may be made better than those I have used, and have given orders to other manufacturers for another set, composed of a somewhat different material; which, however, I have not yet been able to obtain. My object for thus bringing this forward now, is in the bope that some one with time, opportunity, and means, may be induced to take up the subject; as, being about to proceed abroad, I am obliged, for a time at all events, to give up the practical pursuit of this subject.

It is incumbent upon me to acknowledge the valuable assistance I have received from Mr. George Yates, my successor as resident surgeon at this institution, during $m y$ experiments; and I may also state that he is now having made what he designates a railway guide-that is, a small staff with a groove on its under surface, into which other instruments fit, so that the small staff being introduced into the bladder, any larger instrument may be with certainty carried through the urethra.

** Our correspondent is mistaken. The plan of introducing a membranous canal into the urethra has been tried on several occasions, and abandoned. The tubes and guide have now been used with complete success in a great number of cases, and without producing any bad effects in a single instance.-Sub.-ED. L.

\section{a fatiror \\ OF THE PRACTICE OF \\ MEDICINE AND SURGERY IN THE}

\section{HOSPITALS OF LONDON.}

Now that our readers are acquainted with the introductory lectures which have been delivered in the different schools, and the excellent advice contained in them, and having last week attempted a sketch of the best plan which the student of medicine may adopt for reaping the full benefit of the matchless opportunities he has at his command, we shall just offer a few words, in this exclusively nosocomial department of our journal, touching clinical instruction, and the best mode of profiting by it.

We cannot forbear, in the first place, expressing some exultation at the splendid field afforded for observation in the hos. pitals of this metropolis. Disease may here be seen in almost all its forms, as affecting every age; and, in proximity with the pathological phenomena to be observed in the wards, preparations are preserved in the museums, perpetuating, like historical documents, manifestations of a morbid character, as handed down by our predecessors in the thorny path of medical investigation. The valuable stores contained in hospital museums are in general not sufficiently studied and compared with the living specimens in the beds of the institution; and there is no doubt but the pupil would gain much by making himself familiar with the various forms of disease exhibited in the preparations, so as to fit himself for the inspections in the dead-house. If you see phthisis or fracture written over a patient's bed, go and look at the numerous specimens of united bones and tubercular lungs in the museum; if the patient's ticket bears the word apoplexy or hernia, go and look at the preparations exhibiting a clot in the cerebral substance, or a displaced portion of intestine or omentum.

It is also of importance for the pupils now and then to consult the case-books of the hospital, so that they may look over the records of diseases which have been treated in the institution, and are analogous or somewhat similar to those in the wards. We remember an hospital where the principal cases were regularly entered in books supplied with good indices; these books were deposited in the library at the end of each year, and formed valuable records within the immediate reach of the students. We recollect with gratitude the information we gathered from these archives during the first years of our own pupilage. Post-mortem reports are extremely valuable 